\title{
Genetic mapping of a susceptibility locus for disc herniation and spastic paraplegia on 6q23.3-q24.1
}

\author{
M Zortea, A Vettori, C P Trevisan, S Bellini, G Vazza, M Armani, A Simonati, \\ M L Mostaccivolo
}

J Med Genet 2002;39:387-390

See end of article for authors' affiliations

Correspondence to Professor M L

Mostaccivolo, Department of Biology, University of

Padua, Viale $G$ Colombo

3, 35121 Padua, Italy;

mstmls@bio.unipd.it

Revised version received 13 March 2002

Accepted for publication 14 March 2002

\begin{abstract}
It has been suggested that a genetic factor(s) or a familial predisposition may contribute to the clinical manifestations of disc herniation; moreover, no genetic linkage between spinal disc herniation and spastic paraplegia has ever been described.

A family with consanguineous parents and four of eight sibs affected by multiple disc herniations and spastic paraplegia was clinically and genetically analysed. Surgery caused partial improvement in all of them. After the exclusion of type II collagen and vitamin D receptor genes and the recessive loci for HSPs, a genome wide search was performed with about 500 fluorescent markers.

Positive lod score values were obtained for chromosome 6q22.31-q24.1, with evidence of three homozygous intervals. The maximum multipoint lod score of 3.28 was obtained in only one interval, between markers D6S1699 and D6S314. On the whole, a susceptibility locus for disc herniation and autosomal recessive spastic paraplegia was found on chromosome 6q23.3-q24. 1. This is the first time that disc herniation and the associated neurological syndrome has been linked to a human chromosomal region.
\end{abstract}

D isc degeneration with herniation is a common clinical manifestation of spinal column pathology in young and adult people. From a genetic point of view, little information has so far been available on possible susceptibility loci. As far as lumbar disc herniation is concerned, its pathogenesis is usually recognised as being dependent on multiple factors. Among them, it has usually been suggested that a genetic factor or a familial predisposition may be of relevance to the development of disc herniation.

In 1999, Kawaguchi et al ${ }^{1}$ chose a polymorphism (VNTR) in exon 12 of the aggrecan gene as a candidate marker for lumbar disc disease. A shorter number of repeats was present in participants with multilevel and severe disc degeneration, even though no significant correlation was shown between the length of VNTR and the type or the presence of disc herniation. Other candidate genes were presumed to be involved in the pathogenesis of disc diseases, such as glycosaminoglycans or different types of collagen, particularly type II collagen. Recently, Ahsan et al ${ }^{2}$ showed the absence of type II collagen in herniated human intervertebral samples by biochemical and morphological studies, thus postulating its possible involvement in the pathogenesis of disc disease. Videman et al, ${ }^{34}$ investigating the role of the TaqI intragenic polymorphism in the coding region of the vitamin D receptor gene in a cohort of 142 men affected by lumbar spine degeneration, identified a strong association with disc degeneration. It is noteworthy that type II collagen and vitamin D receptor genes map in the same region on chromosome 12q13.11, according to the UCSC Genome Browser database. As far as upper spinal disc herniations and related paraplegia are concerned, similar genetic studies have not yet been reported, in spite of considerable information collected about hereditary spastic paraplegia (HSP). So far, 16 loci have been identified, both on autosomal and X chromosomes. In particular, five are autosomal recessive forms: SPG5 (MIM 270800) on 8pl2q13, ${ }^{5}$ SPG7 (MIM 602783) on 16q24.3, ${ }^{6}$ SPG 11 (MIM 604360) on $15 q_{13},{ }^{7}$ SPG 14 (MIM 605229) on 3q27-q28, and SPG15 on $14 \mathrm{q} .{ }^{9}$ On clinical grounds, spastic paraplegias are characterised by spasticity, hyperreflexia, and progressive lower limb paresis. They may be divided into pure and complicated forms on the basis of additional neurological and/or non-neurological features. ${ }^{10}$

In this study, we analysed an Italian family in which the parents were consanguineous and four of eight sibs had mul- tiple disc herniations and spastic paraplegia. No linkage data for this specific phenotype have been evaluated or described before.

\section{SUBJECTS AND METHODS \\ Clinical analysis}

The family analysed came from the north east of Italy. Four patients (IV.3, IV.4, IV.5, and IV.7, fig 1), belonging to a sibship of eight, were affected by different types of spinal disc herniations and spastic paraplegia. Their unaffected parents were first cousins. No other family members had either disc herniation or paraparesis in the previous generations or in the descendants of the cases considered in this study. All the living members in the fourth generation were neurologically examined by two of us (CPT and MA) as inpatients or outpatients at the Neurological Clinic of Padua University. The clinical features of the four affected subjects are summarised in table 1. In the patients, the onset of the pyramidal symptoms in the lower limbs was of late type with a variation in the age of onset, ranging from 30 (IV.4, fig 1) to 46 years (IV.7). In all of them the paresis was accompanied or preceded by different manifestations of spinal pain irradiating to the upper (IV.4 and IV.5) or the lower limbs (IV.3 and IV.7). All the patients underwent neuroimaging evaluations (CT scan and MRI) in the first years of progression of their paraparesis, which showed different sites of spinal disc herniations: cervical and lumbar in IV.3 and IV.4, cervical in IV.5, and thoracic and lumbar in IV.7. $X$ rays of the shoulders, elbows, hips and knees showed no major abnormalities in any of them, while $x$ rays of the spinal column detected minor spondylosis, mainly in the cervical and the lumbar spine in IV.3 and IV.4, only in the cervical spine in IV.5, and in the whole spine in IV.7. All of them underwent surgical treatment of the disc herniations and they showed a clear, even though partial, improvement of the motor symptoms and complete remission of the neck and back pain. They did not show clear signs of amyotrophy or of sensory deficit of the limbs; however, electromyography showed evidence of mild motor-sensory (IV.3), or sensory (IV.5), or motor (IV.7) neuropathy, without radicular involvement. In these three patients, nerve conduction studies showed only minor abnormalities. In patient IV.4, the same electrophysiological investigations were normal. The variable 


\begin{tabular}{|c|c|c|c|c|c|c|}
\hline Subject & Age $(y)$ & Onset (y) & Clinical signs & Herniation (MRI) & EMG & Other symptoms \\
\hline IV. 3 & 64 & 45 & $\begin{array}{l}\text { Mild low back and right leg pain, severe } \\
\text { paraparesis }\end{array}$ & $\begin{array}{l}\text { C3-C4; C4-C5; } \\
\text { L5-S1 }\end{array}$ & $\begin{array}{l}\text { Mild motor and sensory } \\
\text { neuropathy }\end{array}$ & $\begin{array}{l}\text { Late onset bilateral } \\
\text { cataract }\end{array}$ \\
\hline IV.4 & 62 & 30 & $\begin{array}{l}\text { Mild neck and right arm pain, severe } \\
\text { paraparesis }\end{array}$ & $\begin{array}{l}\text { C5-C6; C6-C7; } \\
\text { L3-L4 }\end{array}$ & Normal & - \\
\hline IV.5 & 61 & 37 & $\begin{array}{l}\text { Moderate neck pain, moderate } \\
\text { paraparesis }\end{array}$ & C4-C5; C5-C6 & Mild sensory neuropathy & - \\
\hline IV.7 & 57 & 46 & Mild leg pain, moderate paraparesis & $\begin{array}{l}\text { D6-D7; D 12-L1 } \\
\text { L1-L2 }\end{array}$ & Mild motor neuropathy & Congenital glaucoma \\
\hline
\end{tabular}

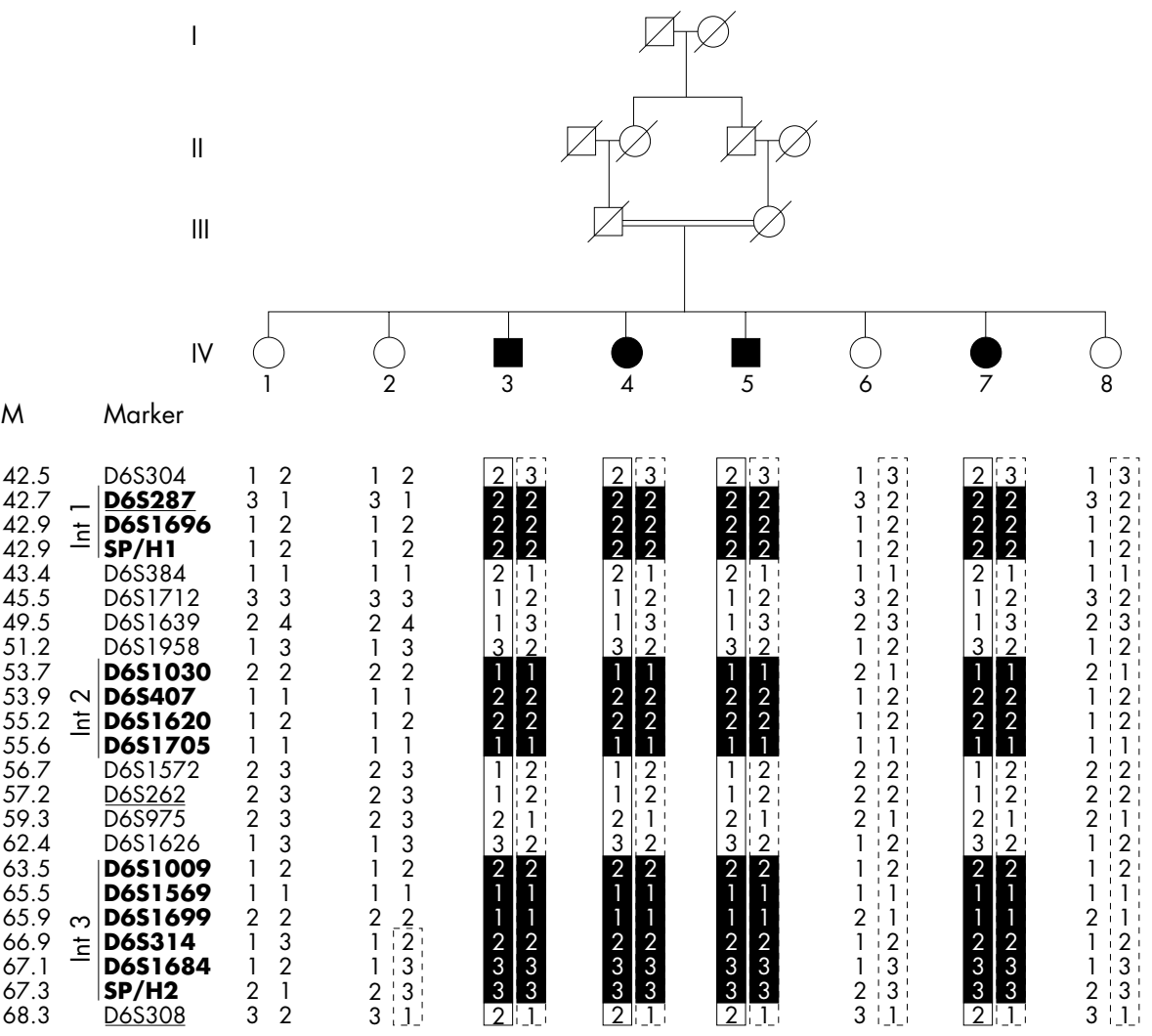

Figure 1 Haplotypes on chromosome 6q22.31-q24.1. The homozygous markers are shown in bold and fluorescent markers are underlined. The two parental haplotypes shared in the whole region by the affected subjects are framed by dashed and continuous boxes. Blackened portions (Int 1, Int 2, and Int 3) represent the homozygous intervals.

electrophysiological signs of neuropathy, found in three of the four affected cases, appeared inconsistent because they were heterogeneous in the clinical presentation and absent in one of the affected sibs. Moreover, the sural nerve biopsy evaluated in one of them (IV.3) detected only minor and non-specific axonal alterations. This minor nerve involvement detected in our patients appeared to be unrelated to the disc herniation, since clinical signs and neurophysiological abnormalities resulting from spinal root compression were not found. Case IV.3 also suffered from bilateral cataract from the age of 59, while case IV.7 was affected by congenital bilateral glaucoma. Two of the clinically unaffected sibs had neuroimaging evaluation of the cervical and the lumbar column, without evidence of any type of disc pathology.

\section{Molecular genetic analysis}

For molecular analysis, blood samples from the eight members of the fourth generation (fig 1) were collected and the DNA extracted from $10 \mathrm{ml}$ of blood by standard methods. ${ }^{11}$ Informed consent was previously obtained, in accordance with current privacy legislation. In order to exclude a possible involvement of the COL2AI and VDR genes, we used two fluorescent markers, D12S85 and D12S368, flanking both these genes.

All the microsatellites relative to the known AR-HSP loci (D8S260 and D8S285 for SPG5, D16S303 and D16S3023 for SPG7, D15S1007 and D15S1012 for SPG11, D3S1294 and D3S2747 for SPG 14, and D14S77 and D14S61 for SPG15) were PCR amplified, analysed on a 9\% denaturing polyacrylamide gel, and silver stained.

A genome wide search was performed using 485 fluorescent markers on autosomal chromosomes. Three hundred and eighty-two were from the ABI PRISM Linkage Mapping Set Version 2 (LMS2, Perkin Elmer) and a further 103 fluorescent markers were selected from the ABI PRISM Linkage Mapping Set High Density 5 (LMS HD5) in order to obtain a better resolution. All these markers were amplified in a PTC-225 Peltier Thermal Cycler (MJ Research). The PCR products were loaded on a $7 \%$ denaturing polyacrylamide (BioRad) gel and separated on an automatic ABI373 sequencer (Applied Biosystems). The data collected were analysed using GENESCAN672 version 1.1 and GENOTYPER version 1.0 software 
Table 2 Two point lod scores for markers in the candidate region $16 q 22.31$. 6q24.1). Fluorescent markers are underlined. The homozygous markers are shown in bold type

\begin{tabular}{|c|c|c|c|c|c|c|c|c|c|}
\hline \multirow[b]{2}{*}{ Marker } & \multicolumn{9}{|c|}{ Lod score at $\theta=$} \\
\hline & 0.00 & 0.01 & 0.05 & 0.10 & 0.20 & 0.30 & 0.40 & $Z \max$ & $\theta \max$ \\
\hline D6S423 & -2.11 & -0.50 & 0.11 & 0.29 & 0.34 & 0.23 & 0.08 & 0.34 & 0.2 \\
\hline D6S261 & -0.59 & 0.99 & 1.47 & 1.49 & 1.21 & 0.75 & 0.26 & 1.49 & 0.1 \\
\hline D6S401 & -0.59 & 0.99 & 1.47 & 1.49 & 1.21 & 0.75 & 0.26 & 1.49 & 0.1 \\
\hline D6S433 & -0.57 & 0.90 & 1.38 & 1.40 & 1.11 & 0.66 & 0.17 & 1.40 & 0.1 \\
\hline D6S304 & -0.65 & 0.89 & 1.36 & 1.38 & 1.08 & 0.63 & 0.19 & 1.38 & 0.1 \\
\hline D6S287 & 2.81 & 2.76 & 2.54 & 2.25 & 1.66 & 1.04 & 0.42 & 2.81 & 0.0 \\
\hline D6S1696 & 1.85 & 1.81 & 1.64 & 1.43 & 1.03 & 0.64 & 0.26 & 1.85 & 0.0 \\
\hline $\mathrm{SP} / \mathrm{H} 1$ & 1.85 & 1.81 & 1.64 & 1.43 & 1.03 & 0.64 & 0.26 & 1.85 & 0.0 \\
\hline D6S384 & -1.54 & -0.02 & 0.53 & 0.64 & 0.56 & 0.33 & 0.07 & 0.64 & 0.1 \\
\hline D6S1712 & -0.57 & 0.90 & 1.38 & 1.40 & 1.11 & 0.66 & 0.17 & 1.40 & 0.1 \\
\hline D6S1639 & -0.59 & 0.99 & 1.47 & 1.49 & 1.21 & 0.75 & 0.26 & 1.49 & 0.1 \\
\hline D6S1958 & -0.65 & 0.89 & 1.36 & 1.38 & 1.08 & 0.63 & 0.19 & 1.38 & 0.1 \\
\hline D6S1030 & 2.61 & 2.55 & 2.34 & 2.07 & 1.51 & 0.91 & 0.32 & 2.61 & 0.0 \\
\hline D6S407 & 2.61 & 2.55 & 2.34 & 2.07 & 1.51 & 0.91 & 0.32 & 2.61 & 0.0 \\
\hline D6S1620 & 1.85 & 1.81 & 1.64 & 1.43 & 1.03 & 0.64 & 0.26 & 1.85 & 0.0 \\
\hline D6S1572 & -0.69 & 0.89 & 1.37 & 1.40 & 1.11 & 0.66 & 0.20 & 1.40 & 0.1 \\
\hline D6S262 & -0.69 & 0.89 & 1.37 & 1.40 & 1.11 & 0.66 & 0.20 & 1.40 & 0.1 \\
\hline D6S975 & -2.11 & -0.50 & 0.11 & 0.29 & 0.34 & 0.23 & 0.08 & 0.34 & 0.2 \\
\hline D6S1626 & -0.65 & 0.89 & 1.36 & 1.38 & 1.08 & 0.63 & 0.19 & 1.38 & 0.1 \\
\hline D6S1009 & 1.85 & 1.81 & 1.64 & 1.43 & 1.03 & 0.64 & 0.26 & 1.85 & 0.0 \\
\hline D6S1699 & 2.61 & 2.55 & 2.34 & 2.07 & 1.51 & 0.91 & 0.32 & 2.61 & 0.0 \\
\hline D6S314 & 2.81 & 2.75 & 2.52 & 2.21 & 1.60 & 0.98 & 0.38 & 2.81 & 0.0 \\
\hline D6S1684 & 2.80 & 2.74 & 2.51 & 2.20 & 1.58 & 0.97 & 0.38 & 2.80 & 0.0 \\
\hline $\mathrm{SP} / \mathrm{H} 2$ & 2.80 & 2.74 & 2.51 & 2.20 & 1.58 & 0.97 & 0.38 & 2.80 & 0.0 \\
\hline D6S308 & -0.65 & 0.89 & 1.36 & 1.38 & 1.08 & 0.63 & 0.19 & 1.38 & 0.1 \\
\hline D6S310 & -0.57 & 0.89 & 1.35 & 1.36 & 1.05 & 0.60 & 0.14 & 1.36 & 0.1 \\
\hline D6S1703 & -1.43 & 0.16 & 0.70 & 0.81 & 0.71 & 0.46 & 0.17 & 0.81 & 0.1 \\
\hline
\end{tabular}

(ABI). To analyse the critical region (6q22.31-q24.1) more precisely, 26 evenly distributed, additional markers were chosen from the Genome Browser database (http:// genome.ucsc.edu). Owing to a lack of informative markers, two CA repeats, which we named SP/H1 and SP/H2, were also selected to define the homozygous regions further, belonging to GenBank clones AL078600 and AL050388, respectively. These two clones are contiguous to the ones containing the homozygous markers D6S1696 and D6S1684, respectively. The primers used were: SP/Hlf: 5' - CACGAGGAAGGGAAGCATAA - 3', SP/Hlr: 5' - GTAGGTTGGTGGGCAGAGAG - 3', SP/H2f: 5' CTTTCACTTTGGGGCCATTA - 3', SP/H2r: 5' - CCTTGGTTC TCTTGGGAAT - 3'. The DNA ( $100 \mathrm{ng}$ ) was amplified in a final volume of $10 \mu \mathrm{l}$ of $1 \times$ RTB buffer, $0.1 \mathrm{mmol} / \mathrm{l}$ of each dNTPs, $500 \mathrm{nmol} / \mathrm{l}$ of each primer, $1.5 \mathrm{mmol} / \mathrm{l} \mathrm{MgCl}_{2}$, and $0.2 \mathrm{U} / \mathrm{\mu l}$ of RTB Taq polymerase in a PTC-225 Peltier Thermal Cycler (MJ Research) using standard PCR conditions and an annealing temperature of $59^{\circ} \mathrm{C}$.

The SLINK program was used to calculate the potential lod score. ${ }^{12}$ Two point linkage analysis was carried out using the MLINK program from the LINKAGE package version 5.2, ${ }^{13}$ assuming autosomal recessive inheritance, complete penetrance, and a disease allele frequency of $10^{-4}$. Equal male and female recombination rates and an equal allele frequency were assumed. Multipoint linkage analysis was performed using GENEHUNTER version 2.1. ${ }^{14}$ The genetic intermarker distances were inferred from the Genome Browser database.

\section{RESULTS}

We began our study by excluding COL2AI and VDR and the known AR-HSP loci (SPG5, SPG7, SPG11, SPG14, and SPG15). The two point lod scores obtained for all the analysed markers were negative, with values $<-2$ at recombination fraction $(\theta)$ $=0.0$ (data not shown).

By a genome wide analysis, almost the entire genome $(\sim 90 \%)$ was excluded. Significant positive lod score values were obtained in region 6q22.31-q24.1 for three consecutive fluorescent markers: D6S287 (Zmax $=2.81$ at $\theta=0.0), \mathrm{D} 6 \mathrm{~S} 262$ $(\mathrm{Zmax}=1.40$ at $\theta=0.1)$, and D6S308 $(\mathrm{Zmax}=1.38$ at $\theta=0.1)$. Because of the homozygous status shared only by the affected subjects for the alleles of marker D6S287 and the closeness of the lod score of this marker to the computer simulated one ( simulated $\mathrm{Zmax}=2.88$ ), we decided to investigate this region further by means of 26, evenly distributed, additional markers. Table 2 shows the lod score values for only 24 markers, because D6S1705 and D6S1569 are not informative. The haplotype analysis carried out for this region (about $26 \mathrm{cM}$ ) confirmed homozygous status shared only by the affected subjects in the three intervals, as shown in fig l. Interval 1 spans $0.9 \mathrm{cM}$ between markers D6S304 and D6S384 on 6q22.31, interval 2 spans $5.5 \mathrm{cM}$ between markers D6S1958 and D6S1572 on 6q22.33-q23.1, and interval 3 spans $6 \mathrm{cM}$ between markers D6S1626 and D6S308 on 6q23.3-q24.1 and is defined by six homozygous consecutive markers. Multipoint analysis using GENEHUNTER software, performed for intervals 2 and 3, gave a maximum lod score of 2.58 (between markers D6S407 and D6S1620) and of 3.28 (between markers D6S1699 and D6S314), respectively. These results gave evidence of linkage between the phenotype peculiar to this family and region $6 \mathrm{q} 23.3-\mathrm{q} 24.1$

\section{DISCUSSION}

A major disc herniation of the cervical or dorsal column causes compression of the spinal cord with the clinical consequence of a pyramidal disturbance affecting the lower limbs. The whole pyramidal syndrome, including spasticity, deep tendon hyperreflexia, Babinski's sign and partial (paraparesis) or complete (paraplegia) impairment of intentional movement of the lower limbs, is also the characteristic clinical phenotype of hereditary spastic paraplegia (HSP), the well known primary degeneration of the cortical spinal tracts, without spinal abnormalities. Even though familial aggregation has 
been observed in intervertebral disc degeneration, from a genetic point of view the few available reports on spinal disc herniation were association studies with polymorphisms found in two genes: an exonic VNTR in the AGCl and an intronic TaqI polymorphism in the VDR gene. This approach, however, is of non-parametric type; indeed, cohorts of patients have always been considered instead of families with clear mendelian heredity. For this reason, no linkage studies have ever been published.

In the family analysed in this study, two particular traits were evident: (1) clear mendelian transmission (autosomal recessive) and (2) a compound phenotype. The four affected cases had consanguineous parents and showed a paraparetic syndrome associated with upper and lower spine disc herniations. Because of this particular phenotype, never previously described, the first, compulsory step of our analysis was the exclusion of the COL2AI and VDR genes (involved in disc degeneration) and the AR-HSP loci. On the basis of these preliminary results, we continued with the analysis using the homozygosity mapping method, finding positive lod score values spread over a large region (about $26 \mathrm{cM}$ ) only on chromosome 6q22.31-q24.1. A better definition of the whole region showed three homozygous intervals of varying size. The multipoint analysis yielded significant results for interval $3(6$ $\mathrm{cM}$ ), with a peak of $\mathrm{Zmax}=3.28$, whereas for interval 2 (5.5 cM) this value was 2.58. Given that for this kind of analysis the accepted threshold value is 3 , we initially focused our attention on interval 3. On the other hand, in our opinion, a value of 2.58 still warrants further analysis, should the search within interval 3 not yield any results.

The identification of a candidate region is a first step in the search for a gene linked to a disease. The subsequent step is the analysis of the physiological and structural traits of the tissue involved in the disease, in order clearly to identify what gene(s) may play a crucial role in its pathogenesis. As far as disc herniation is concerned, the intervertebral discs consist mainly of collagens and proteoglycans. The latter confer rigidity and resistance to compression and are responsible for the high water content, while the former prevent breakage. On these bases, it is reasonable to consider these genes as playing a role in the genetic predisposition to disc herniation.

Another important step in the identification of candidate genes is also to consider the structural and functional features shared by the products of the genes previously described and linked to other variants of the same disease. In the case of autosomal HSPs, it should be noted that, even though the three genes mapped so far (paraplegin, ${ }^{15}$ spastin, ${ }^{16}$ and atlastin ${ }^{17}$ ) encode proteins belonging to different families, the products of two genes (paraplegin and spastin) both contain an AAA motif. The third autosomal gene (atlastin) does not contain this motif, but instead shows great homology to guanylate binding protein 1 ( $G B P 1$ ); for this reason, atlastin may belong to the dynamin family of large GTPases. Dynamins are important for the rapid and efficient recycling of the synaptic vesicles and have been found associated with cytoskeletal elements, including microtubules. ${ }^{18}$

For the analysis of the candidate region (interval 3) in the family reported in this study, we referred to MapViewer (http:/www.ncbi.nlm.nih.gov/) and the Genome Browser Database; in this region spanning about $5 \mathrm{Mb}, 16$ known genes and four Unigene EST clusters have been reported. On the basis of a preliminary analysis of the characteristics of these genes, none of them seems to have functional or structural homology to proteoglycans or collagens, while a gene, $M A P 7$, microtubule associated protein 7 , may be a candidate gene for HSP.

All together, these data provided evidence of a susceptibility locus for multiple herniation and paraplegia on chromosome 6q23.3-q24.1. In conclusion, studying other families with similar clinical and genetic characteristics may provide further information to help define this disease locus better. This study also indicates that possible overlooked spinal column pathology should be considered in patients with apparent primary autosomal recessive HSP.

\section{ACKNOWLEDGEMENTS}

This work was supported by Telethon grant No 797 to MLM and by "Legato Destro" grant to CPT. We wish to thank the members of the family for their cooperation in this study.

\section{Authors' affiliations}

M Zortea, A Vettori, S Bellini, G Vazza, M L Mostaccivolo, Department of Biology, University of Padua, Padua, Italy M Zortea, C P Trevisan, M Armani, Department of Neurological and Psychiatric Sciences, University of Padua, Padua, Italy

A Simonati, Department of Neurological and Visual Sciences, University of Verona, Verona, Italy

\section{REFERENCES}

1 Kawaguchi $Y$, Osada R, Kanamori M, Ishihara H, Ohmori K, Matsui H, Kimura T. Association between an aggrecan gene polymorphism and lumbar disc degeneration. Spine 1999:24:2456-60.

2 Ahsan R, Tajima N, Chosa E, Sugamata M, Sumida M, Hamada M. Biochemical and morphological changes in herniated human intervertebral disc. J Orthop Sci 2001;6:510-18

3 Videman T, Leppavuori J, Kaprio J, Battie MC, Gibbons LE, Peltonen L, Koskenvuo M. Intragenic polymorphisms of the vitamin D receptor gene associated with intervertebral disc degeneration. Spine 1998;23:2477-85

4 Videman T, Gibbons LE, Battie MC, Maravilla K, Vanninen E, Leppavuori J, Kaprio J, Peltonen L. The relative roles of intragenic polymorphisms of the vitamin $d$ receptor gene in lumbar spine degeneration and bone density. Spine $2001 ; 26$ :E7-12.

5 Hentati A, Pericak-Vance MA, Hung WY, Belal S, Laing N, Boustany RM, Hentati F, Ben Hamida M, Siddique T. Linkage of "pure" autosomal recessive familial spastic paraplegia to chromosome 8 markers and evidence of genetic locus heterogeneity. Hum Mol Genet 1994;3:1263-7.

6 De Michele G, De Fusco M, Cavalcanti F, Filla A, Marconi R, Volpe G, Monticelli A, Ballabio A, Casari G, Cocozza S. A new locus for autosomal recessive hereditary spastic paraplegia maps to chromosome 16q24.3. Am J Hum Genet 1998;63:135-9.

7 Martinez Murillo F, Kobayashi H, Pegoraro E, Galluzzi G, Creel G. Mariani C, Farina E, Ricci E, Alfonso G, Pauli RM, Hoffman EP. Genetic localization of a new locus for recessive familial spastic paraplegia to 15q13-15. Neurology 1999:53:50-6.

8 Vazza G, Zortea M, Boaretto F, Micaglio GF, Sartori V, Mostacciuolo $M L A$ new locus for autosomal recessive spastic paraplegia (SPG 14) associated with distal motor neuropathy and mental retardation maps to chromosome 3q27-q28. Am J Hum Genet 2000;67:504-9.

9 Hughes CA, Byrne PC, Webb S, McMonagle P, Patterson V, Hutchinson $M$, Parfrey NA. SPG 15, a new locus for autosomal recessive complicated HSP on chromosome 14q. Neurology 2001;56:1230-3.

10 Harding AE. Classification of the hereditary ataxias and paraplegias. Lancet 1983;i: $1151-5$.

11 Miller SA, Dykes DD, Poleski HF. A simple salting out procedure for extracting DNA from human nucleated cells. Nucleic Acids Res 1988; 16:55

12 Weeks DE, Ott J, Lathrop GM. SLINK: a general simulation program for linkage analysis. Am J Hum Genet Suppl 1990;47:A204.

13 Lathrop GM, Lalouel JM., Julier C, Ott J. Strategies for multilocus linkage analysis in humans. Proc Natl Acad Sci USA 1984;81:3443-6.

14 Kruglyak L, Daly M, Reeve-Daly MP, Lander ES. Parametric and nonparametric linkage analysis: a unified multipoint approach. Am J Hum Genet 1996;58:1347-63

15 Casari G, De Fusco M, Ciarmatori S, Zeviani M, Mora M, Fernandez $P$ De Michele G, Filla A, Cocozza S, Marconi R, Durr A, Fontaine B, Ballabio A. Spastic paraplegia and OXPHOS impairment caused by mutations in paraplegin, a nuclear-encoded mitochondrial metalloprotease. Cell 1998;93:973-83.

16 Hazan J, Fonknechten N, Mavel D, Paternotte C, Samson D, Artiguenave F, Davoine CS, Cruaud C, Durr A, Wincker P, Brottier P, Cattolico L, Barbe V, Burgunder JM, Prud'homme JF, Brice A, Fontaine B Heilig B, Weissenbach J. Spastin, a new AAA protein, is altered in the most frequent form of autosomal dominant spastic paraplegia. Nat Genet 1999;23:296-303.

17 Zhao X, Alvarado D, Rainier S, Lemons R, Hedera P, Weber CH, Tukel T, Apak M, Heiman-Patterson T, Ming L, Bui M, Fink JK. Mutations in a newly identified GTPase gene cause autosomal dominant hereditary spastic paraplegia. Nat Genet 2001;29:326-31.

18 Ochoa GC, Slepnev VI, Neff L, Ringstad N, Takei K, Daniell L, Kim W, Cao H, McNiven M, Baron R, De Camilli P. A functional link between dynamin and the actin cytoskeleton at podosomes. J Cell Biol 2000;150:377-89. 